\title{
The role of physical and cognitive function in performance of activities of daily living in patients with mild-to-moderate Alzheimer's disease - a cross-sectional study
}

Frederikke K Clemmensen ${ }^{1}$, Kristine Hoffmann², Volkert Siersma ${ }^{3}$, Nanna Sobol ${ }^{4}$, Nina Beyer ${ }^{4}$, Birgitte B Andersen ${ }^{1}$, Asmus Vogel ${ }^{1}$, Annette Lolk ${ }^{5}$, Hanne Gottrup ${ }^{6}$, Peter Høgh², Gunhild Waldemar', Steen G Hasselbalch ${ }^{1}$ and Kristian S Frederiksen ${ }^{1 *}$ (D)

\begin{abstract}
Background: Several factors may play a role in the ability of patients with Alzheimer's disease to perform activities of daily living (ADL). The aim of this study was to examine the impact of different aspects of physical performance and cognitive functions on ADL in patients suffering from mild-to-moderate Alzheimer's disease.
\end{abstract}

Methods: We conducted secondary analyses on cross-sectional baseline data from the randomized controlled multicentre study "Preserving quality of life, physical health and functional ability in Alzheimer's Disease: The effect of physical exercise" (ADEX). In total, 185 AD patients (76 women and 109 men), with a mean age on 70,4 years, were included. Data from physical performance tests (Astrand cycle test, Timed up \& Go (TUG), Sit to Stand test (STS)) and cognitive tests (Mini Mental Status Examination (MMSE), Symbol Digit Modalities Test (SDMT), Stroop Color and Word test (Stroop)) were used. Their associations with ADL, measured on the ADCS-ADL scale was assessed in multivariable regression analyses.

Results: SDMT and MMSE had significant, moderate correlations with total ADL (SDMT: $r=0.33$, MMSE: $r=0.42$ ) and instrumental ADL (SDMT: $r=0.31$, MMSE: $r=0.42$ ), but not with basic ADL. Adjusting for age and sex, the associations between SDMT and MMSE to total ADL and instrumental ADL persisted. No significant associations were found between Astrand, TUG, STS or Stroop and total ADL, basic ADL or instrumental ADL.

\footnotetext{
* Correspondence: kristian.steen.frederiksen@regionh.dk

'Danish Dementia Research Centre, Department of Neurology, Rigshospitalet,

Copenhagen University Hospital, Blegdamsvej 9 - section 8025, 2100

Copenhagen, Denmark

Full list of author information is available at the end of the article
}

(c) The Author(s). 2020 Open Access This article is licensed under a Creative Commons Attribution 4.0 International License, which permits use, sharing, adaptation, distribution and reproduction in any medium or format, as long as you give appropriate credit to the original author(s) and the source, provide a link to the Creative Commons licence, and indicate if changes were made. The images or other third party material in this article are included in the article's Creative Commons licence, unless indicated otherwise in a credit line to the material. If material is not included in the article's Creative Commons licence and your intended use is not permitted by statutory regulation or exceeds the permitted use, you will need to obtain permission directly from the copyright holder. To view a copy of this licence, visit http://creativecommons.org/licenses/by/4.0/ The Creative Commons Public Domain Dedication waiver (http://creativecommons.org/publicdomain/zero/1.0/) applies to the data made available in this article, unless otherwise stated in a credit line to the data. 


\begin{abstract}
(Continued from previous page)
Conclusion: Total $A D L$ and instrumental $A D L$ are associated with cognitive functions, including executive function. No significant association between examined physical performance parameters and ADL functions was observed, and consequently does not support an impact of physical function on ADL functions in patients with mild-to-moderate Alzheimer's disease and relatively well-preserved physical function. Strategies aimed to improve cognition may be better suited to improve ADL function in patients with mild-to-moderate Alzheimer's disease.
\end{abstract}

Trial registration: NCT01681602. Registered 10 September 2012, retrospectively registered.

Keywords: Alzheimer's disease, Dementia, Physical function, Aerobic exercise, Activity of daily living, Cognition, Executive functions

\section{Background}

Alzheimer's disease $(\mathrm{AD})$ is a neurodegenerative disease with early and prominent memory impairment, and decline in the ability to independently carry out activities of daily living (ADL) [1-3]. ADL functions may be divided into basic ADL (BADL) (e.g. eating and personal hygiene) and instrumental ADL (IADL) (e.g. using a telephone and shopping) [4]. IADL have been found to decline in early stages and may be more related to cognitive abilities, while BADL decline in more advanced stages and may be less dependent on cognitive functioning [5].

Several patient-related factors such as cognitive function, neuropsychiatric symptoms and disease duration may have deleterious impact on ADL functions in AD [68], patients with Mild Cognitive Impairment (MCI) [9] and in older adults receiving domiciliary care [10]. Moreover, physical performance of the patients (e.g. balance, strength and aerobic capacity) is likely to play a role. For example, the Timed Up and Go (TUG), a measure of basic mobility, has been shown to predict future functional dependency in a large cohort [11]. Environment-related factor may also affect the ability of patients to perform ADL including spatial layout [12], lighting [13], design of dining rooms [14] and access to outdoor areas [15]. This clearly indicates that the performance of ADL is a complex process reliant on both cognitive and physical performance of the patient as well as the environment inhabited by the patient. A further example of the intricacies of mobility, ADL and cognition was found in a study looking at strategies employed by patients with dementia to perform "sit to stand". Patients with dementia on average employed more different strategies than cognitively unimpaired [16]. For patients with dementia "Sit to stand" remains an important function to be able to perform in order to maintain ADL [17].

With regards to the relationship between cognition and $\operatorname{ADL}[1,2,18]$, deterioration of executive function has been specifically associated with poorer performance on ADL functions in patients with Alzheimer's disease [19-22]. Physical exercise has been found to improve the ability to perform ADL functions in both AD patients [23-26] and in community-dwelling older adults
[27-30], although results are not consistent across studies in either populations [31,32].

Other interventions have also shown to be able to improve ADL in patients with $\mathrm{MCI}$ and dementia. For example, a combination of cognitive-physical training has shown beneficial in both patients with dementia and MCI [33]. The approach of combined cognitive-motor exercise, i.e. training both cognitive abilities and motor skills/physical performance has been shown to possibly improve ADL functions in MCI patients [34], and may be superior to physical exercise alone [35]. Further, cognitive rehabilitation interventions may also improve $\mathrm{ADL}$, as well as cognitive training. These interventions usually involve repeated sessions where either a specific $\mathrm{ADL}$ function (e.g. making coffee) is trained (cognitive rehabilitation) or where underlying cognitive functions which may sub serve ADL functions are trained. Both approaches has been shown to possibly improve ADL functions as well as cognitive functions in patients with dementia [36-38]. A recent meta-analysis found an impact of multicomponent training interventions (aerobic, strength, postural and balance exercise) on ADL, but not on cognitive function and physical fitness, reinforcing the importance of analyzing subdomain changes through more specific outcomes, also considering different stages of dementia [39].

Preservation of executive function, rather than memory, has been linked to slower decline in ADL in AD patients [40] and further, executive function, but not memory, has been found to correlate with IADL in non-demented older adults [41] and has been found to explain more of the variance in IADL [42]. The abovementioned suggests that executive function may be more important than memory for performing ADL functions. Numerous studies have shown that aerobic fitness, strength and balance can be improved in patients with dementia [43]. Physical exercise has also been found to improve cognitive function in patients with MCI and dementia $[44,45]$. Further, especially executive functions may be specifically positively affected by physical exercise in AD [46-49] as well as in healthy older persons [50-52]. 
A better understanding of the individual contributions of different cognitive functions and the impact of physical performance would potentially enable targeted interventions aimed at improving ADL functions. As stated above many studies have investigated the relationship between physical performance, cognition and ADL, in isolation. However, how all three variables are related still remains unclear. An exception is a rather recent cross-sectional study in which it was reported that the relationship between aerobic fitness and ADL function in AD patients was mediated by global cognition [53].

The objectives of the present study were to examine the possible association between physical performance, cognition, and ADL functions. We hypothesised that physical performance and cognition, respectively, were associated with $\mathrm{ADL}$ functions. Further we hypothesised that IADL is more cognitively taxing than BADL, and therefore less dependent of physical function and the converse regarding IADL. Further, we wished to assess the impact of physical performance and cognitive functions on $\mathrm{ADL}$, and to examine the possible mediating role of cognitive function with regards to the relationship between physical performance and ADL function.

\section{Methods}

\section{Study design}

This is a secondary analysis of cross-sectional data from a previously conducted randomized controlled trial using baseline data from patients enrolled in the ADEX study (Preserving quality of life, physical health and functional ability in Alzheimer's disease: The effect of physical exercise study). The ADEX study was a multicentre single-blinded study, conducted between January 2012 and June 2014, investigating the impact of a 16-week aerobic exercise intervention on symptoms of $\mathrm{AD}[45,54]$. Flow chart of the study is presented in Fig. 1. The ADEX study was approved by the Danish National Committee on Biomedical Research Ethics (H-3-2011-128) and written informed consent was obtained from each participant prior to enrolment.

\section{Participants}

A total of 200 community-dwelling patients with mild-tomoderate AD were included in the ADEX study, all meeting criteria for probable AD according to the Alzheimer's criteria by the National Institute of Neurological and Communicative Disorders and Stroke and the Alzheimer's Disease and Related Disorders (NINDS-ADRDA), McKhann et al., 1984. All participants were diagnosed by a physician who was a specialist in either geriatric medicine, psychiatry or neurology. As a part of the diagnostic process, all subjects underwent as a minimum formal cognitive testing, ADL assessment, blood samples and structural brain scans (CT or MRI). Patients were recruited from and followed in 8 memory clinics in Denmark. Details on objectives and design including inclusion and exclusion criteria have

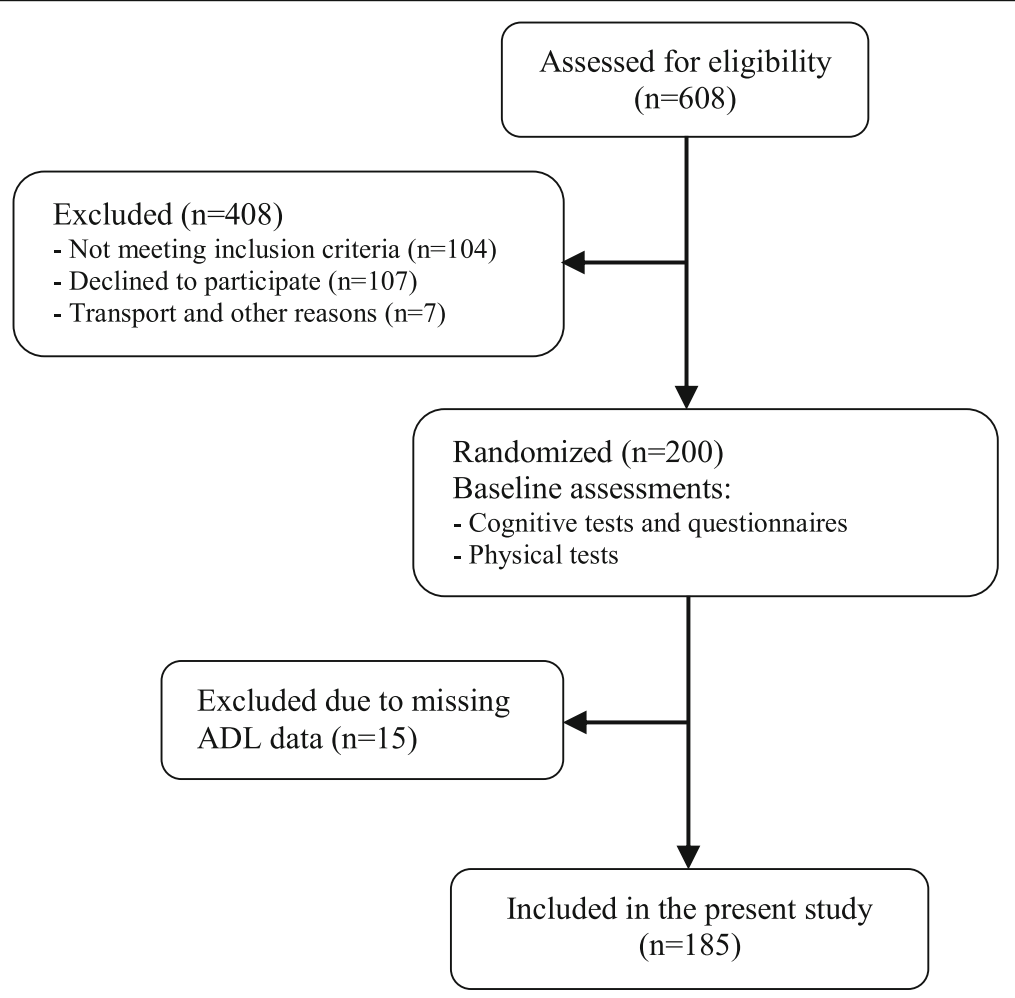

Fig. 1 Flow chart of the ADEX study 
previously been described in detail [54]. For the present study, 185 of the 200 participants (92.5\%) had sufficient baseline data for variables of interest and were included in the present study.

\section{Cognitive assessments}

Cognitive assessments were performed in a quiet environment without interruptions. The Mini-Mental State Examination (MMSE) was used to assess global cognitive function [55]. Processing speed and attention were assessed by the Symbol Digit Modalities Test (SDMT). For the present study, the number of correct responses within a 120-s response time was used [56]. The Stroop Colour and Word Test was applied to assess executive control and inhibition [57]. In this study, the number of words the participant read in $45 \mathrm{~s}$ (maximum score of 100) in the colour word test (incongruent version) was used for analysis.

\section{Assessments of physical performance}

To assess aerobic fitness, the 6-min Astrand Cycle Ergometer test (Monark Ergomedic 839E, Monark Exercise AB, Sweden) was used. The estimated maximum oxygen uptake $\left(\mathrm{VO}_{2} \mathrm{max}(\mathrm{ml} / \mathrm{kg} / \mathrm{min})\right)$ based on workload and average heart rate during the last minute of the test, corrected for age and body weight [58], was calculated. The Timed Up \& Go test (TUG) was used to assess basic mobility [59]. The $30 \mathrm{~s}$ chair stand test, sit to stand (STS) was used to assess strength and endurance in the lower extremities [60].

\section{Assessment of activities of daily living}

ADL was assessed by the Alzheimer's Disease Co-operative Study - ADL (ADCS-ADL) scale [4]. The ADCS-ADL scale assesses $23 \mathrm{ADL}$ items and is administered to the caregiver as an interview. The scale comprises two components; basic ADL (BADL) consisting of six items such as self-feeding, personal hygiene, and dressing, and instrumental ADL (IADL) consisting of 17 items such as using the telephone, reading books or magazines, managing finances, leisure activities and household chores. The BADL score ranges from 0 to 22 and the IADL from 0 to 56 . Together BADL and IADL comprise total ADL with the range 0-78. The higher score indicates less impairment.

\section{Statistical analysis}

Unadjusted associations between total ADL, BADL and IADL, and measures of physical performance (Astrand test, TUG, STS) and cognitive function (MMSE; Stroop and SDMT) were assessed by Pearson's correlation coefficient. Using multivariable linear regression models the beforementioned relationships were examined (adjusted for age and sex) by the corresponding $\beta$-coefficients where the measures of physical performance and cognitive function where entered individually. In order to assess a potential mediating effect of cognition on the association between physical performance and $\mathrm{ADL}$, the regressions for the measures of physical performance were additionally adjusted for the measures of cognitive functions (MMSE, Stroop and SDMT). A small number of patients had missing data for Stroop, SDMT and Astrand, which were handled with listwise deletion. Statistical analyses were performed using SAS v9.4 and $\mathrm{R}$ v3.5.1. Statistical significance was accepted at $p<0.05$.

\section{Results}

Baseline characteristics for all 185 participants included in the study are presented in Table 1 . The average age was 70.4 years, with a mean MMSE score of 24.6. Seventy-six (41\%) participants were women. The mean total ADL was 64.2, indicating mildly affected ADL. Participants were in general in good health with very few comorbidities (see Table 1), below that of average patients with AD [61].

Pearson correlation coefficients (PCC) are presented in Table 2. SDMT was significantly and positively correlated with total ADL $(r=0.33, P<0.05)$ and IADL $(r=0.31$, $P<0.05)$, but not with BADL. Moreover, MMSE was positively and significantly correlated with total ADL $(r=0.42, P<0.05)$ and IADL $(r=0.42, P<0.05)$, but not with BADL. None of the physical parameters nor Stroop were correlated with ADL.

Table 1 Demographics

\begin{tabular}{ll}
\hline Characteristics & N 185Mean (SD)185 \\
\hline Age, years (SD) & $70.4(7.4)$ \\
Gender (women), $n$ (\%) & $76(41 \%)$ \\
Comorbidities, $\boldsymbol{n}$ (\%) & $75(40,5)$ \\
Hypertension & $18(9,7)$ \\
Diabetes & $68(36,8)$ \\
Hypercholesterolemia & $3(1,6)$ \\
Apoplexia & $3(1,6)$ \\
Acute myocardial infarction & $0(\%)$ \\
Walking aid & \\
Cognitive performance, mean (SD) & $24.6(3.0)$ \\
MMSE & $27.3(14.3)$ \\
SDMT & $18.4(9.8)$ \\
Stroop & \\
Physical performance, mean (SD) & $25.9(8.2)$ \\
Astrand (VO,max) & $6.6(1.5)$ \\
TUG (sec) & $14.6(3.9)$ \\
STS (number in 30 s) & \\
Activities of Daily Living, mean (SD) & $64.2(9.3)$ \\
ADL & $21.1(1.6)$ \\
BADL & $43.0(8.8)$ \\
IADL & \\
\hline
\end{tabular}

MMSE Mini Mental State Examination, SDMT Symbol Digit Modalities Test, $A D L$ Activities of Daily Living, BADL Basic ADL, IADL Instrumental ADL, TUG Timed Up \& Go, STS Sit to Stand 
Table 2 Correlation and Regression coefficients

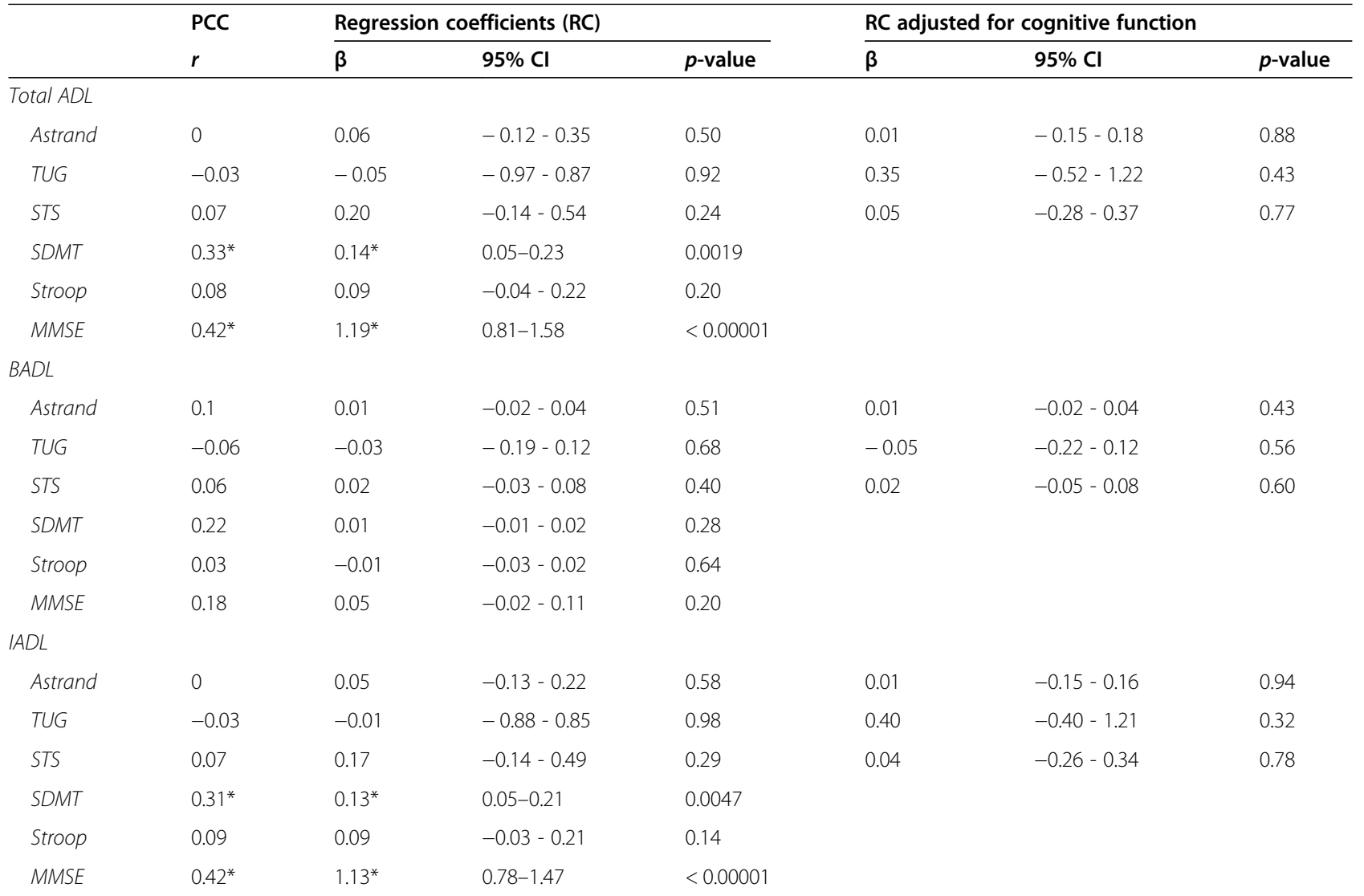

${ }^{*} P<0.05$. All regression coefficients are adjusted for sex and age. $P C C$ Pearson Correlation Coefficient, $A D L$ Activities of daily living, $B A D L$ Basic ADL, IADL Instrumental ADL, TUG Timed up \& go, STS Sit to stand, MMSE Mini mental state examination, SDMT SYMBOL Digit Modalities Test, RC regression coefficients

The corresponding $\beta$-coefficients from multivariable linear regression models, adjusted for age and sex, are presented in Table 2. Results show that SDMT was associated with total ADL $(\beta=0.14, p=0.0019)$ and IADL $(\beta=0.13$, $p=0.0047)$. Similarly, MMSE was associated with total ADL $(\beta=1.19, p<0.00001)$ and IADL $(\beta=1.13, p<$ 0.00001). Concerning BADL, no significant associations with physical nor cognitive parameters were found. No significant associations were found between Astrand, TUG, STS or Stroop and ADL, BADL or IADL.

Since no association between physical performance parameters and $\mathrm{ADL}$ functions were found, a mediating effect of cognition was not excepted. However, the regressions for physical performance parameters adjusted for the measures of cognitive functions are presented in Table 2. These results show a minor change for total ADL and IADL, where the $\beta$-coefficient for Astrand and STS decreases, while the $\beta$-coefficient for TUG increases. No change was observed in BADL.

\section{Discussion}

In the present study, we add to the limited research on how physical performance and cognitive subdomains impact on ADL in patients with mild-to-moderate $\mathrm{AD}$.
We found that cognition and ADL were significantly and positively correlated. Specifically, with regards to cognitive domains we found that processing speed and attention correlated significantly with IADL but not BADL. The findings support our hypothesis that cognitive function is of importance for ADL functions and especially for more complex ADL functions captured by IADLs [3]. Measures of physical performance were not associated with ADL. To our knowledge this is the largest study to date examining the relationship between ADL, aerobic function and cognition.

In general, a significant moderate correlation was observed between general cognitive function and the instrumental subscale of ADL, while no correlation was found to basic ADL, suggesting that IADL is more reliant on cognition. When examining the relationship in more detail, processing speed and attention were found to be associated with total ADL and IADL, but not BADL, mirroring the findings for general cognitive function. As peviously stated, the findings may indicate that those complex activities comprising IADL are most reliant on cognition. Supporting this finding, IADL has been found to be more strongly associated with executive function than BADL in patients with mild-to-moderate $\mathrm{AD}[21,62]$. Moreover, in older adults without dementia deterioration in executive function is 
independently correlated with the rate of change in IADL, and may be more deleterious, even in the presence of memory deficits [41]. However, it should be kept in mind that the participants included in the present study suffered from mild-to-moderate $\mathrm{AD}$. Therefore, these findings may also reflect that IADL was primarily affected, as compared to BADL which is typically affected in later stages of dementia [5]. This is also in line with the findings in the present study.

Another important finding is the lack of significant association between ADL functions and physical performance i.e. aerobic fitness, measure of mobility, and strength and endurance of lower extremities, which is not consistent with the findings of a recent meta-analysis establishing an association between TUG and STS and worsening in ADL in populations of older adults [63]. Our results may indicate that physical performance does not have a significant impact on ADL functions in our sample of AD patients in the mild to moderate stage. Considering that participants in our study were likely more physically fit compared to AD patients in general, a ceiling effect on physical performance measures is also possible. Furthermore, the participants were also relatively unimpaired in ADL function, which together may have masked a possible relationship. Nevertheless, our findings are in accordance with a similar recent study, which to our knowledge is the first study to examine the impact of aerobic fitness on ADL, in which no direct effect of aerobic fitness on ADL functions was found [53]. Yu et al. further found that the relationship between aerobic fitness and ADL was mediated by a number of factors including global cognition. Although we did not find a significant mediating effect of cognition between physical performance and ADL, we did observe a decrease in the $\beta$-coefficients for the physical performance parameters concerning ADL and IADL (Table 2), which may nevertheless indicate some mediating effect of cognition.

Our findings add to the relatively limited research on the role of aerobic and physical performance on ADL in patients with $\mathrm{AD}$. The findings provide important input for future design of interventions aimed at improving ADL. Our findings of an association between cognitive function, and specifically a measure of procession speed and mental speed, indicate that interventions in patients with mild to moderate $\mathrm{AD}$ focusing on improving these cognitive functions may be more beneficial for improving ADL. The fact that we did not find an association between ADL and aerobic performance would seem to indicate that in mild to moderate $\mathrm{AD}$, interventions to improve $\mathrm{ADL}$ functions may be less effective, if targeting aerobic function. It may be speculated, based on our findings that in more advanced patients, interventions improving aerobic and physical performance may improve ADL through an effect on BADL. In order to further investigate the impact of physical performance on ADL, especially considering recent research regarding effects of cognitive-motor interventions on ADL $[35,39]$, it would be interesting to investigate the association between domain specific cognitive decline, decline in physical performance and in ADL functions in a cognitivemotor intervention study on $\mathrm{AD}$ patients.

We acknowledge that this study has some limitations. The study is a cross-sectional study excluding an analysis of a causal relationship. Analyses of intervention is of interest in order to investigate how physical performance, cognition and ADL benefit from physical exercise [43, 45]. However, this study focused on the mutual relationship between the three parameters and not the impact of the intervention on this relationship. The study included a selected group of patients with relative mild cognitive symptoms and relatively physically fit, prior to an intervention with physical exercise, potentially excluding patients with greater impairment in $\mathrm{ADL}$. Therefore, selection bias is a risk, and the results may not be generalizable to all patients with $\mathrm{AD}$, e.g. patients with more impairment in ADL, less physically fit patients, or patients with more comorbidities. We did not control for comorbidities in the statistical analysis, as our population had relatively few comorbidities, but we cannot exclude that these did not affect our results, which we acknowledge as a limitation. Further, we acknowledge that the low variability in our sample group concerning physical performance, could potentially underestimate the associations. This is a secondary analysis of data from a previously conducted intervention trial, and it cannot be ruled out that the study was underpowered. We acknowledge that several physical barriers affect ADL functions, and that impairment in ADL is most likely caused by multiple factors. However, it is not possible to take all such factors into account and the main focus in this study was on selected physical and cognitive tests. The ADCS-ADL scale assesses different aspects of everyday living but may not capture all relevant aspects of ADL. It is a strength that our large group of patients are well characterized and have been assessed using a diverse number of scales and physical performance measures.

\section{Conclusion}

In conclusion, this study found a significant and positive association between cognition, including processing speed and attention and total ADL and IADL functions in patients with mild-to-moderate AD. No association was found between cognition and BADL, suggesting that BADL is less cognitively demanding and less reliant on cognitive function. Although our findings do not support physical function as being important for performance of ADL functions in patients with mild-to-moderate $\mathrm{AD}$ and with relatively well-preserved physical function, it cannot be interpreted as if such an association does not exist in persons with more severe dementia or more severe ADL impairment. Our study could imply that interventions targeting cognition 
may also have a positive effect on instrumental ADL in patients with mild-to-moderate AD.

\section{Abbreviations}

AD: Alzheimer's Disease; ADCS-ADL: Alzheimer's Disease Co-operative Study - Activities of Daily Living; ADL: Activities of Daily Living; BADL: Basic Activities of Daily Living; IADL: Instrumental Activities of Daily Living; MCl: Mild Cognitive Impairment; MMSE: Mini Mental Status Examination; NINDS-ADRDA: National Institute of Neurological and Communicative Disorders and Stroke and the Alzheimer's Disease and Related Disorders Association; PCC: Pearson correlation coefficients; SDMT: Symbol Digit Modalities Test; Stroop: Stroop Colour and Word test; STS: Sit to Stand test; TUG: Timed up \& Go

\section{Acknowledgements}

The Absalon Foundation of May 1st 1978. Professor, DMSc, MD Gunhild Waldemar and professor, DMSc, MD Steen G. Hasselbalch, Danish Dementia Research Center, Department of Neurology, Copenhagen University Hospital, Rigshospitalet, Denmark, who are the ADEX study program director, and the national principal investigator, respectively. Associate professor Nina Beyer, Department of Physical and Occupational Therapy and Institute of Sports Medicine, Copenhagen University Hospital, Bispebjerg, Denmark, who is project director of the physical exercise program, of the ADEX trial, a multicenter study with eight participating sites in Denmark. We wish to thank all memory clinic investigators by site as follows: Memory Clinic, Copenhagen University Hospital, Rigshospitalet - Birgitte Bo Andersen, DMSc, MD; Memory Clinic, Zealand University Hospital, Roskilde Hospital - Peter Høgh, PhD, MD; Memory Clinic, Aalborg University Hospital - Karsten Vestergaard, MD; Memory Clinic, Aarhus University Hospital - Hans Brændgaard, MD, Hanne Gottrup, PhD, MD; Dementia Clinic, Odense University Hospital - Anette Lolk, Assoc. Professor, PhD, MD, Lene Wermuth, MD, Department of Geriatrics, Odense University Hospital, Svendborg Hospital - Søren Jakobsen, MD; Department of Geriatrics, Slagelse Hospital Lars P. Laugesen, MD, Robert Graff Gergelyffy, MD; Memory Clinic, Glostrup University Hospital - Eva Bjerregaard, MD.

A special thanks to all physiotherapists, study nurses and clinical raters for their contributions to the ADEX study. We thank all participants and relatives, without whom the study would not have been possible.

\section{Authors' contributions}

FKC contributed to the study design, interpretation of data and drafted the manuscript. VS contributed to the study design and performed the statistical analyses. $\mathrm{KH}, \mathrm{NS}, \mathrm{NB}, \mathrm{BBA}, \mathrm{AL}, \mathrm{HG}, \mathrm{PH}$ contributed to the study design, collected data and revised the manuscript. AV contributed to the study design, interpretation of data and revised the manuscript. GW contributed to the study design and revised the manuscript. SGH contributed to the study concept, study design, and revised the manuscript. KSF contributed to the study concept, study design and revised the manuscript. All authors read and approved the final manuscript.

\section{Funding}

This work was supported by The Danish Council for Strategic Research (J. no.: 10-092814). Additional funding was obtained by The Lundbeck Foundation (grant number FP 73/2012). The Danish Dementia Research Centre is supported by grants from the Danish Ministry of Health (J.no.: 2007-12143-112, project 59506/J. no: 0901110, project 34501); and the Danish Health Foundation (J. no.: 2007B004). All researchers were independent from the funders, and the funders were not involved in the collection, analysis, and interpretation of data, in writing the manuscript, or in submission of the article for publication.

\section{Availability of data and materials}

The datasets used and analysed in this study are available from the corresponding author on reasonable request.

\section{Ethics approval and consent to participate}

The ADEX study was approved by the Danish National Committee on Biomedical Research Ethics (H-3-2011-128). An overseeing mental health expert deemed all adult patients ethically and medically capable of providing consent for their participation in the research presented in this manuscript. Written, informed consent was obtained from each participant prior to enrolment.

\section{Consent for publication}

Not applicable.

\section{Competing interests}

The authors declare that they have no competing interests.

\section{Author details}

${ }^{1}$ Danish Dementia Research Centre, Department of Neurology, Rigshospitalet, Copenhagen University Hospital, Blegdamsvej 9 - section 8025, 2100 Copenhagen, Denmark. ${ }^{2}$ Regional Dementia Research Centre, Department of Neurology, Zealand University Hospital, Roskilde, Denmark. ${ }^{3}$ Research Unit for General Practice and Section of General Practice, Department of public health, University of Copenhagen, Copenhagen, Denmark. ${ }^{4}$ Department of Physical and Occupational Therapy and Institute of Sports Medicine, Bispebjerg Hospital, University of Copenhagen, Copenhagen, Denmark. ${ }^{5}$ Dementia Clinic, Odense University Hospital, Odense, Denmark. ${ }^{6}$ Dementia Clinic, Aarhus University Hospital, Aarhus, Denmark.

Received: 22 April 2020 Accepted: 23 November 2020

Published online: 27 November 2020

\section{References}

1. Wajman JR, Oliveira FF, Marin SMC, Schultz RR, Bertolucci PHF. Is there correlation between cognition and functionality in severe dementia? The value of a performance-based ecological assessment for Alzheimer's disease. Arq Neuropsiquiatr. 2014;72(11):845-50

2. Arrighi HM, Gelinas I, McLaughlin TP, Buchanan J, Gauthier S. Longitudinal changes in functional disability in Alzheimer's disease patients. Int Psychogeriatr. 2013;25(6):929-37.

3. Kahle-Wrobleski K, Coley N, Lepage B, Cantet C, Vellas B, Andrieu S. Understanding the complexities of functional ability in Alzheimer's disease: more than just basic and instrumental factors. Curr Alzheimer Res. 2014; 11(4):357-66.

4. Galasko D, Bennett D, Sano M, Ernesto C, Thomas R, Grundman M, et al. An inventory to assess activities of daily living for clinical trials in Alzheimer's disease. The Alzheimer's disease cooperative study. Alzheimer Assoc Disord. 1997;11(Suppl 2):S33-9.

5. Liu-Seifert H, Siemers E, Selzler K, Sundell K, Aisen P, Cummings J, et al. Correlation between cognition and function across the Spectrum of Alzheimer's disease. J Prev Alzheimers Dis. 2016;3(3):138-44.

6. Benke T, Delazer M, Sanin G, Schmidt H, Seiler S, Ransmayr G, et al. Cognition, gender, and functional abilities in Alzheimer's disease: how are they related? J Alzheimers Dis. 2013;35(2):247-52.

7. D'Onofrio G, Sancarlo D, Panza F, Copetti M, Cascavilla L, Paris F, et al. Neuropsychiatric symptoms and functional status in Alzheimer's disease and vascular dementia patients. Curr Alzheimer Res. 2012;9(6):759-71.

8. Palmer K, Lupo F, Perri R, Salamone G, Fadda L, Caltagirone C, et al. Predicting disease progression in Alzheimer's disease: the role of neuropsychiatric syndromes on functional and cognitive decline. J Alzheimers Dis. 2011:24(1):35-45.

9. Jekel K, Damian M, Wattmo C, Hausner L, Bullock R, Connelly PJ, et al. Mild cognitive impairment and deficits in instrumental activities of daily living: a systematic review. Alzheimers Res Ther. 2015;7(1):17.

10. Helvik AS, Høgseth LD, Bergh S, Šaltytè-Benth J, Kirkevold Ø, Selbæk G. A 36-month follow-up of decline in activities of daily living in individuals receiving domiciliary care. BMC Geriatr. 2015:15:47.

11. Lee JE, Chun H, Kim YS, Jung HW, Jang IY, Cha HM, et al. Association between timed up and go test and subsequent functional dependency. J Korean Med Sci. 2020;35(3):e25.

12. Marquardt G, Schmieg P. Dementia-friendly architecture: environments that facilitate wayfinding in nursing homes. Am J Alzheimers Demen. 2009;24(4): $333-40$

13. Riemersma-van der Lek RF, Swaab DF, Twisk J, Hol EM, Hoogendijk WJ, Van Someren EJ. Effect of bright light and melatonin on cognitive and noncognitive function in elderly residents of group care facilities: a randomized controlled trial. Jama. 2008;299(22):2642-55.

14. Nijs KA, de Graaf C, Kok FJ, van Staveren WA. Effect of family style mealtimes on quality of life, physical performance, and body weight of 
nursing home residents: cluster randomised controlled trial. Bmj. 2006; 332(7551):1180-4.

15. Detweiler MB, Murphy PF, Myers LC, Kim KY. Does a wander garden influence inappropriate behaviors in dementia residents? Am J Alzheimers Demen. 2008;23(1):31-45.

16. Dolecka UE, Ownsworth T, Kuys SS. Comparison of sit-to-stand strategies used by older adults and people living with dementia. Arch Gerontol Geriatr. 2015;60(3):528-34.

17. Slaughter SE, Estabrooks CA. Optimizing the mobility of residents with dementia: a pilot study promoting healthcare aide uptake of a simple mobility innovation in diverse nursing home settings. BMC Geriatr. 2013;13:110.

18. Suh GH, Ju YS, Yeon BK, Shah A. A longitudinal study of Alzheimer's disease: rates of cognitive and functional decline. Int J Geriatr Psychiatry. 2004;19(9):817-24.

19. Martyr A, Clare L. Executive function and activities of daily living in Alzheimer's disease: a correlational meta-analysis. Dement Geriatr Cogn Disord. 2012;33(2-3):189-203.

20. Pereira FS, Yassuda MS, Oliveira AM, Forlenza OV. Executive dysfunction correlates with impaired functional status in older adults with varying degrees of cognitive impairment. Int Psychogeriatr. 2008;20(6):1104-15.

21. Saari T, Hallikainen I, Hanninen T, Raty H, Koivisto A. Relationships between cognition and activities of daily living in Alzheimer's disease during a 5-year follow-up: ALSOVA study. J Alzheimers Dis. 2018;64(1):269-79.

22. Swanberg MM, Tractenberg RE, Mohs R, Thal LJ, Cummings JL. Executive dysfunction in Alzheimer disease. Arch Neurol. 2004;61 (4):556-60.

23. Littbrand $H$, Stenvall M, Rosendahl E. Applicability and effects of physical exercise on physical and cognitive functions and activities of daily living among people with dementia: a systematic review. Am J Phys Med Rehabil. 2011;90(6):495-518.

24. Forbes D, Thiessen EJ, Blake CM, Forbes SC, Forbes S. Exercise programs for people with dementia. Cochrane Database Syst Rev. 2013;12:Cd006489.

25. Forbes D, Forbes SC, Blake CM, Thiessen EJ, Forbes $S$. Exercise programs for people with dementia. Cochrane Database Syst Rev. 2015;4:Cd006489.

26. Rao AK, Chou A, Bursley B, Smulofsky J, Jezequel J. Systematic review of the effects of exercise on activities of daily living in people with Alzheimer's disease. Am J Occup Ther. 2014;68(1):50-6.

27. Boyle PA, Buchman AS, Wilson RS, Bienias JL, Bennett DA. Physical activity is associated with incident disability in community-based older persons. J Am Geriatr Soc. 2007:55(2):195-201.

28. Vermeulen J, Neyens JC, van Rossum E, Spreeuwenberg MD, de Witte LP. Predicting ADL disability in community-dwelling elderly people using physical frailty indicators: a systematic review. BMC Geriatr. 2011:11:33.

29. Tak E, Kuiper R, Chorus A, Hopman-Rock M. Prevention of onset and progression of basic ADL disability by physical activity in community dwelling older adults: a meta-analysis. Ageing Res Rev. 2013;12(1):329-38.

30. Chou CH, Hwang CL, Wu YT. Effect of exercise on physical function, daily living activities, and quality of life in the frail older adults: a meta-analysis. Arch Phys Med Rehabil. 2012;93(2):237-44.

31. Toots A, Littbrand $\mathrm{H}$, Lindelof $\mathrm{N}$, Wiklund $\mathrm{R}$, Holmberg $\mathrm{H}$, Nordstrom $\mathrm{P}$, et al. Effects of a high-intensity functional exercise program on dependence in activities of daily living and balance in older adults with dementia. J Am Geriatr Soc. 2016;64(1):55-64.

32. Gine-Garriga M, Roque-Figuls M, Coll-Planas L, Sitja-Rabert M, Salva A. Physical exercise interventions for improving performance-based measures of physical function in community-dwelling, frail older adults: a systematic review and meta-analysis. Arch Phys Med Rehabil. 2014;95(4):753-769.e3.

33. Karssemeijer EGA, Aaronson JA, Bossers WJ, Smits T, Olde Rikkert MGM, Kessels RPC. Positive effects of combined cognitive and physical exercise training on cognitive function in older adults with mild cognitive impairment or dementia: a meta-analysis. Ageing Res Rev. 2017;40:75-83.

34. Reijnders J, van Heugten C, van Boxtel M. Cognitive interventions in healthy older adults and people with mild cognitive impairment: a systematic review. Ageing Res Rev. 2013;12(1):263-75.

35. Hagovska M, Nagyova I. The transfer of skills from cognitive and physical training to activities of daily living: a randomised controlled study. Eur J Ageing. 2017;14(2):133-42.

36. Bahar-Fuchs A, Martyr A, Goh AM, Sabates J, Clare L. Cognitive training for people with mild to moderate dementia. Cochrane Database Syst Rev. 2019;3:CD013069.

37. Clare L, Kudlicka A, Oyebode JR, Jones RW, Bayer A, Leroi I, et al. Goaloriented cognitive rehabilitation for early-stage Alzheimer's and related dementias: the GREAT RCT. Health Technol Assess Winch Engl. 2019;23(10): $1-242$.
38. Amieva H, Robert PH, Grandoulier A-S, Meillon C, De Rotrou J, Andrieu S, et al. Group and individual cognitive therapies in Alzheimer's disease: the ETNA3 randomized trial. Int Psychogeriatr. 2016;28(5):707-17.

39. Machado FB, Silva N, Farinatti P, Poton R, Ribeiro Ó, Carvalho J. Effectiveness of multicomponent exercise interventions in older adults with dementia: a meta-analysis. Gerontologist. 2020;16:89.

40. Pillai JA, Bonner-Jackson A, Walker E, Mourany L, Cummings JL. Higher working memory predicts slower functional decline in autopsy-confirmed Alzheimer's disease. Dement Geriatr Cogn Disord. 2014;38(3-4):224-33.

41. Royall DR, Palmer R, Chiodo LK, Polk MJ. Executive control mediates memory's association with change in instrumental activities of daily living: the freedom house study. J Am Geriatr Soc. 2005;53(1):11-7.

42. Royall DR, Lauterbach EC, Kaufer D, Malloy P, Coburn KL, Black KJ. The cognitive correlates of functional status: a review from the committee on research of the American neuropsychiatric association. J Neuropsychiatr Clin Neurosci. 2007;19(3):249-65.

43. Sobol NA, Hoffmann K, Frederiksen KS, Vogel A, Vestergaard K, Braendgaard $\mathrm{H}$, et al. Effect of aerobic exercise on physical performance in patients with Alzheimer's disease. Alzheimers Dement. 2016:12(12):1207-15.

44. Groot C, Hooghiemstra AM, Raijmakers PG, van Berckel BN, Scheltens P, Scherder EJ, et al. The effect of physical activity on cognitive function in patients with dementia: a meta-analysis of randomized control trials. Ageing Res Rev. 2016;25:13-23.

45. Hoffmann K, Sobol NA, Frederiksen KS, Beyer N, Vogel A, Vestergaard K, et al. Moderate-to-high intensity physical exercise in patients with Alzheimer's disease: a randomized controlled trial. J Alzheimers Dis. 2016;50(2):443-53.

46. Farina $\mathrm{N}$, Tabet $\mathrm{N}$, Rusted J. Habitual physical activity (HPA) as a factor in sustained executive function in Alzheimer-type dementia: a cohort study. Arch Gerontol Geriatr. 2014;59(1):91-7.

47. Yu F, Vock DM, Barclay TR. Executive function: responses to aerobic exercise in Alzheimer's disease. Geriatr Nurs. 2018;39(2):219-24.

48. Guitar NA, Connelly DM, Nagamatsu LS, Orange JB, Muir-Hunter SW. The effects of physical exercise on executive function in community-dwelling older adults living with Alzheimer's-type dementia: a systematic review. Ageing Res Rev. 2018;47:159-67.

49. Sobol NA, Hoffmann K, Vogel A, Lolk A, Gottrup H, Hogh P, et al. Associations between physical function, dual-task performance and cognition in patients with mild Alzheimer's disease. Aging Ment Health. 2016;20(11):1139-46

50. Wilbur J, Marquez DX, Fogg L, Wilson RS, Staffileno BA, Hoyem RL, et al. The relationship between physical activity and cognition in older Latinos. J Gerontol B Psychol Sci Soc Sci. 2012;67(5):525-34.

51. Colcombe $\mathrm{S}$, Kramer AF. Fitness effects on the cognitive function of older adults: a meta-analytic study. Psychol Sci. 2003;14(2):125-30.

52. Netz Y, Dwolatzky T, Zinker Y, Argov E, Agmon R. Aerobic fitness and multidomain cognitive function in advanced age. Int Psychogeriatr. 2011; 23(1):114-24.

53. Yu F, Chen Y, Mathiason MA, Wan Q, Lin FV. Cognitive and physical factors affecting daily function in Alzheimer's disease: a cross-sectional analysis. Nurs Health Sci. 2019;21(1):14-20.

54. Hoffmann K, Frederiksen KS, Sobol NA, Beyer N, Vogel A, Simonsen AH, et al. Preserving cognition, quality of life, physical health and functional ability in Alzheimer's disease: the effect of physical exercise (ADEX trial): rationale and design. Neuroepidemiology. 2013;41(3-4):198-207.

55. Folstein MF, Folstein SE, McHugh PR. "Mini-mental state". A practical method for grading the cognitive state of patients for the clinician. J Psychiatr Res. 1975;12(3):189-98.

56. Smith A. Symbol digit modalities test (SDMT). Manual (revised). Los Angeles: Western Psychological Services; 1982.

57. Golden CJ. Stroop color and word test: a manual for clinical and experimental uses. Wood Dale: Stoelting Company; 1978.

58. Cink RE, Thomas TR. Validity of the Astrand-Ryhming nomogram for predicting maximal oxygen intake. Br J Sports Med. 1981;15(3):182-5.

59. McGough EL, Kelly VE, Logsdon RG, McCurry SM, Cochrane BB, Engel JM, et al. Associations between physical performance and executive function in older adults with mild cognitive impairment: gait speed and the timed "up \& go" test. Phys Ther. 2011;91(8):1198-207.

60. Eggermont LH, Gavett BE, Volkers KM, Blankevoort CG, Scherder EJ, Jefferson $\mathrm{AL}$, et al. Lower-extremity function in cognitively healthy aging, mild cognitive impairment, and Alzheimer's disease. Arch Phys Med Rehabil. 2010;91(4):584-8. 
61. Guthrie B, Payne K, Alderson P, McMurdo ME, Mercer SW. Adapting clinical guidelines to take account of multimorbidity. Bmj. 2012;345: e6341.

62. Cornelis E, Gorus E, Van Schelvergem N, De Vriendt P. The relationship between basic, instrumental, and advanced activities of daily living and executive functioning in geriatric patients with neurocognitive disorders. Int J Geriatr Psychiatry. 2019;34(6):889-99.

63. Wang DXM, Yao J, Zirek Y, Reijnierse EM, Maier AB. Muscle mass, strength, and physical performance predicting activities of daily living: a metaanalysis. J Cachexia Sarcopenia Muscle. 2020;11(1):3-25.

\section{Publisher's Note}

Springer Nature remains neutral with regard to jurisdictional claims in published maps and institutional affiliations.

Ready to submit your research? Choose BMC and benefit from:

- fast, convenient online submission

- thorough peer review by experienced researchers in your field

- rapid publication on acceptance

- support for research data, including large and complex data types

- gold Open Access which fosters wider collaboration and increased citations

- maximum visibility for your research: over $100 \mathrm{M}$ website views per year

At BMC, research is always in progress.

Learn more biomedcentral.com/submissions 